\title{
Nonsuppressible Insulin-Like
}

\section{Activity in Human Serum}

\author{
III. DIFFERENTIATION OF TWO DISTINCT \\ MOLECULES WITH NONSUPPRESSIBLE ILA
}

\author{
A. Jakob, Ch. Hauri, and E. R. Froesch \\ From the Metabolic Unit, Department of Medicine, University of Zurich, \\ Switzerland
}

A в S т R A C T Total nonsuppressible insulin-like activity (ILA) of human plasma (measured by the adipose tissue assay) results from the additive effects of at least two distinct components. They differ in molecular size, solubility in acid-ethanol, and in thermostability. More than $90 \%$ of nonsuppressible ILA of human plasma is insoluble in acid-ethanol. Its molecular size of 100,000-150,000 remains unchanged by treatment with acid-ethanol, $5 \mathrm{~m}$ acetic acid- $0.15 \mathrm{~m} \mathrm{NaCl}$, urea, and EDTA. It is inactivated by heat.

Approximately $5 \%$ of total nonsuppressible serum ILA is soluble in acid-ethanol. The molecular weight is $6000-10,000$ after partial purification on Sepadex G-75 (acetic acid- $\mathrm{NaCl}$ ). This molecule is thermostabile for $3 \mathrm{hr}$ at $80^{\circ} \mathrm{C}$.

When the acid-ethanol soluble molecule with nonsuppressible ILA is chromatographed on Sephadex G-100 at neutral $\mathrm{pH}$, it is eluted in a broad peak corresponding to a molecular weight of approximately 50,000-70,000. When rechromatographed on Sephadex G-75 (acetic acid- $\mathrm{NaCl}$ ) its $\mathrm{mol}$ wt is irreversibly converted from 70,000 to 6000 .

Part of the results of this work have been presented in preliminary form by E. R. Froesch, A. Jakob, and A. Labhart at the Sixth Congress of the International Diabetes Federation, Stockholm, 1967.

Address requests for reprints to Dr. A. Jakob, Metabolic Unit, Department of Medicine, Kantonsspital, University of Zurich, Switzerland.

Received for publication 10 April 1968 and in revised form 9 September 1968.
Most of the insulin-like activity retained on Dowex-50 ("bound insulin") is eluted off Sephadex G-75 (acetic acid-NaCl) at the same column volume as the small molecular weight nonsuppressible ILA. The latter molecule is retained on Dowex-50, whereas big molecular weight nonsuppressible ILA is not.

\section{INTRODUCTION}

Serum and other biological fluids are known to act on several metabolic processes of muscle and adipose tissue in vitro in a manner comparable to crystalline insulin (1-5). Insulin-like activity of plasma (ILA) is only partially suppressed by anti-insulin serum, whereas the biological activity of crystalline insulin is completely neutralized $(6,7)$. The fraction of serum ILA that is not influenced by insulin-antibodies and that cannot be measured by immunoassay procedures was termed "nonsuppressible ILA" by Froesch et al. (8) and "atypical insulin" by Samaan, Fraser, and Dempster (9).

A protein with nonsuppressible ILA with a mol wt of 6000 to 10,000 was extracted and partially purified from a human plasma protein fraction and its biochemical and biological properties were studied in vitro and in vivo (10-12). Purified nonsuppressible ILA mimics the effects of crystalline insulin on all metabolic processes investigated to date.

Serum ILA was also investigated in other lab- 
oratories by various biochemical techniques and different bioassay procedures (for reviews, see 13-15). Part of the controversy about the biochemical nature of serum ILA may be due to methodological differences. However, no agreement on simple physicochemical properties of nonsuppressible ILA was obtained by different authors, even when the same methodological tools were used. The mol wt of nonsuppressible ILA of native serum was estimated in two different laboratories by gel-filtration to be approximately $150,000(10,16)$. After extraction and purification nonsuppressible ILA was reported by several different groups of investigators to have a mol wt greater than 100,000 (17), 50,000-70,000 (18, 19 ), and 6000 (10), respectively.

These findings could be explained in two ways. Either nonsuppressible ILA is exerted by one single protein molecule that forms polymers or aggregates with other proteins, or nonsuppressible ILA is exerted by several chemically distinct proteins.

The present studies demonstrate the existence of two different proteins with nonsuppressible ILA in serum. The results also explain why only $1 \%$ of total nonsuppressible ILA was extracted by acid-ethanol and recovered with a mol wt of 6000 (10).

\section{METHODS}

Plasma extraction and fractionation. The procedures are schematically shown on a flow sheet in Fig. 1. Human plasma was obtained by centrifugation of blood from outdated transfusion units. The blood had been collected by the Swiss Red Cross and was kept at $5^{\circ} \mathrm{C}$ for no longer than 4 days after the expiration date. Plasma was lyophilized, treated with acetone-ethanol $(1: 1 \mathrm{v} / \mathrm{v}$, 3-4-ml/g of protein, $-10^{\circ} \mathrm{C}$ ) and washed 3-4 times with the same amount of acetone-ethanol. The precipitate was then dried at room temperature. In the following it will be referred to as acetone powder. This powder was homogenized in ammonium acetate buffer $(0.1 \mathrm{M}, \mathrm{pH} 7.2)$ at room temperature and cooled to $4^{\circ} \mathrm{C}$ (final concentration $100 \mathrm{mg} / \mathrm{ml}$ ). To 16 volumes of this solution a mixture of 48 volumes of ethanol $(96 \%)$ and 1 volume of concentrated $\mathrm{HCl}$ was added, shaken and left at $4^{\circ} \mathrm{C}$ for $30 \mathrm{~min}$. After centrifugation the precipitate was reextracted with a mixture of water, $96 \%$ ethanol, concentrated $\mathrm{HCl}(16: 48: 1 \mathrm{v} / \mathrm{v})$ and the supernatants were combined. In the following, material derived from the acid-ethanol supernatant will be designated as fraction $\mathrm{S}$ and material derived from acid-ethanol precipitate as fraction $P$. The supernate was then brought to $\mathrm{pH}$ 8.5 by $1 \mathrm{~N} \mathrm{NaOH}$ and passed through filter paper

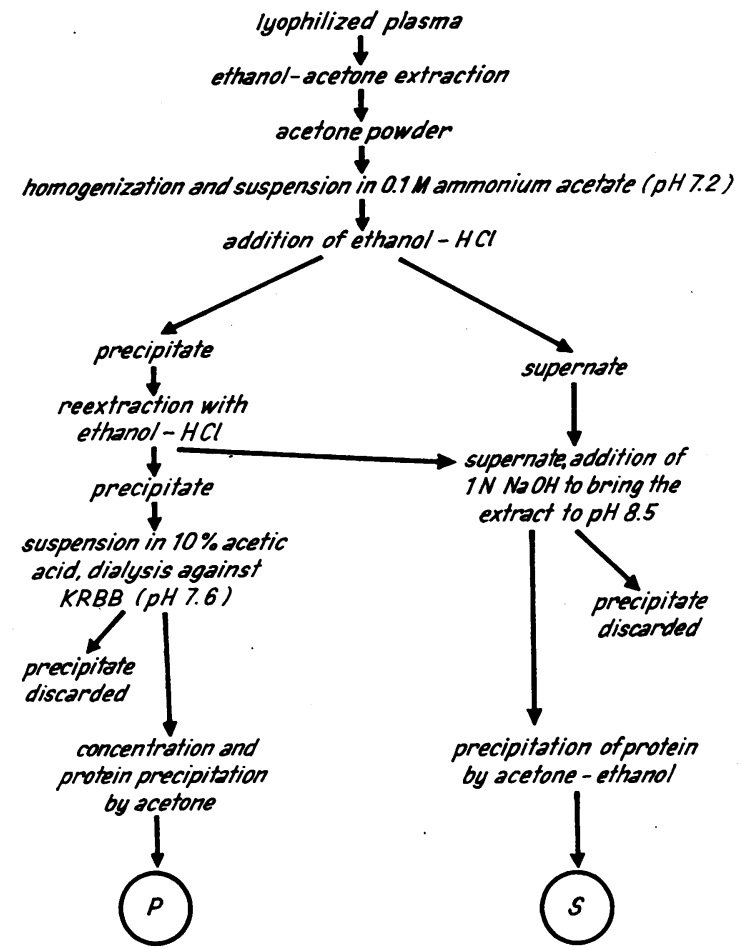

FIGURE 1 Extraction and purification procedures for nonsuppressible ILA.

(Schleicher and Schuell No. 588), cooled to $-10^{\circ} \mathrm{C}$ and added to 4 volumes of an acetone-ethanol mixture $(5: 3$ $\mathrm{v} / \mathrm{v})$ at $-10^{\circ} \mathrm{C}$. After $12 \mathrm{hr}$ at $-10^{\circ} \mathrm{C}$ the supernatant was decanted and the precipitate dried at room temperature (fraction $\mathrm{S}$ ).

The acid-ethanol precipitate was suspended in cold acetone $\left(-10^{\circ} \mathrm{C}\right)$, centrifuged, and the precipitate resuspended with cold acetone in order to wash out the $\mathrm{HCl}$. When dried at room temperature a white powder was obtained. It was dissolved in $10 \%$ acetic acid and dialysed against Krebs-Ringer bicarbonate buffer $\mathrm{pH}$ 7.6. During extensive dialysis at room temperature a heavy precipitate formed and was centrifuged off. The clear supernatant-solution was concentrated 10 to 20 times by ultrafiltration under vacuum and the protein was then precipitated by the addition of 5 volumes of cold acetone. An appreciable purification was achieved by this procedure. After centrifugation the precipitate was dried at room temperature (fraction $\mathrm{P}$ ).

These extractions and the subsequently described gelfiltration procedures were also applied to a Cohn fraction (precipitate B) of human plasma which had been used by Bürgi et al. (10).

Gel-filtration. The columns of Sephadex were prepared as previously reported and the void volume $\left(V_{0}\right)$ was determined with blue dextran 2000 (Pharmacia) (10). The elution volume $\left(V_{\mathbf{r}}\right)$ is expressed as per cent of total bed volume.

Column A, Sephadex G-200 and column B, Sephadex G-100: both equilibrated with $0.1 \mathrm{M}$ ammonium acetate 
buffer ( $\mathrm{pH} 7.2$ ). Column C, Sephadex G-75 in $5 \mathrm{M}$ acetic acid- $0.15 \mathrm{M} \mathrm{NaCl}$ : fractions were pooled for the determination of nonsuppressible ILA after the measurement of the OD at $280 \mathrm{~m} \mu$. The pools were dialysed against water, evaporated to dryness, and redissolved in Krebs-Ringer bicarbonate buffer for the bioassay.

Ion-exchange chromatography. Nonsuppressible ILA of fractions $\mathrm{S}$ and $\mathrm{P}$ was prepared in sufficient amounts for ion-exchange chromatography as follows. Fraction $S$ obtained from precipitate $B$ was purified on a column $\mathrm{C}$ (total bed volume of 3 liters). The material eluted at a volume corresponding to a mol wt of approximately 6000 , and was desalted and lyophilized. It contained $1.8 \mathrm{mU}$ of nonsuppressible ILA/mg of protein.

Fraction $\mathrm{P}$ prepared from precipitate $\mathrm{B}$ was purified on the same column $C$. The material eluted with void volume of the column was again desalted, lyophilized, and assayed $(100 \mu \mathrm{U} / \mathrm{mg}$ of protein). Dowex-50 W $\times 8,100$ 200 mesh, was prepared by the procedure of Antoniades et al. (20) and used in the $\mathrm{Na}^{+}$-cycle, $\mathrm{pH} 6.6 \pm 0.2$. Glass columns were used for chromatography. The ratio of sample to resin volume varied from $1: 3$ to $1: 6$. After passage of the sample into the column, the column was washed with 2 volumes of $0.15 \mathrm{M} \mathrm{NaCl}$ ( $\mathrm{NaCl}$ wash). Proteins retained on the column eluted with $0.02 \mathrm{~N}$ $\mathrm{NH}_{4} \mathrm{OH}$ into $0.2 \mathrm{~N} \mathrm{H}_{2} \mathrm{SO}$, under constant stirring (alkaline eluate). The $\mathrm{NaCl}$ wash and alkaline eluate were prepared for the bioassay by lyophilization and dialysis as outlined by Poffenbarger, Ensinck, Hepp, and Williams (18).

Inactivation. Fraction $\mathrm{P}$ was dissolved in KrebsRinger bicarbonate buffer to give a concentration of approximately $250 \mu \mathrm{U} / \mathrm{ml}$ of nonsuppressible ILA. Mercaptoethanol and urea were added (final concentration, 0.13 and $7 \mathrm{M}$, respectively). After flushing with nitrogen the vials were incubated for $4 \mathrm{hr}$ at $37^{\circ} \mathrm{C}$. The assay for nonsuppressible ILA was performed after extensive dialysis against Krebs-Ringer bicarbonate buffer. In one experiment ILA of fraction $\mathrm{P}$ was incubated for $6 \mathrm{hr}$ with urea and EDTA $(8 \mathrm{M}, 0.2 \%)$, dialysed against water and concentrated before gel-filtration on Sephadex G-75 (5 M acetic acid-0.15 $\mathrm{M} \mathrm{NaCl}$ ) was performed.

Assay of nonsuppressible ILA. The adipose tissue assay described earlier was used $(8,10)$. Anti-bovine insulin serum from guinea pigs was added in excess for all determinations of nonsuppressible ILA. The incuba-

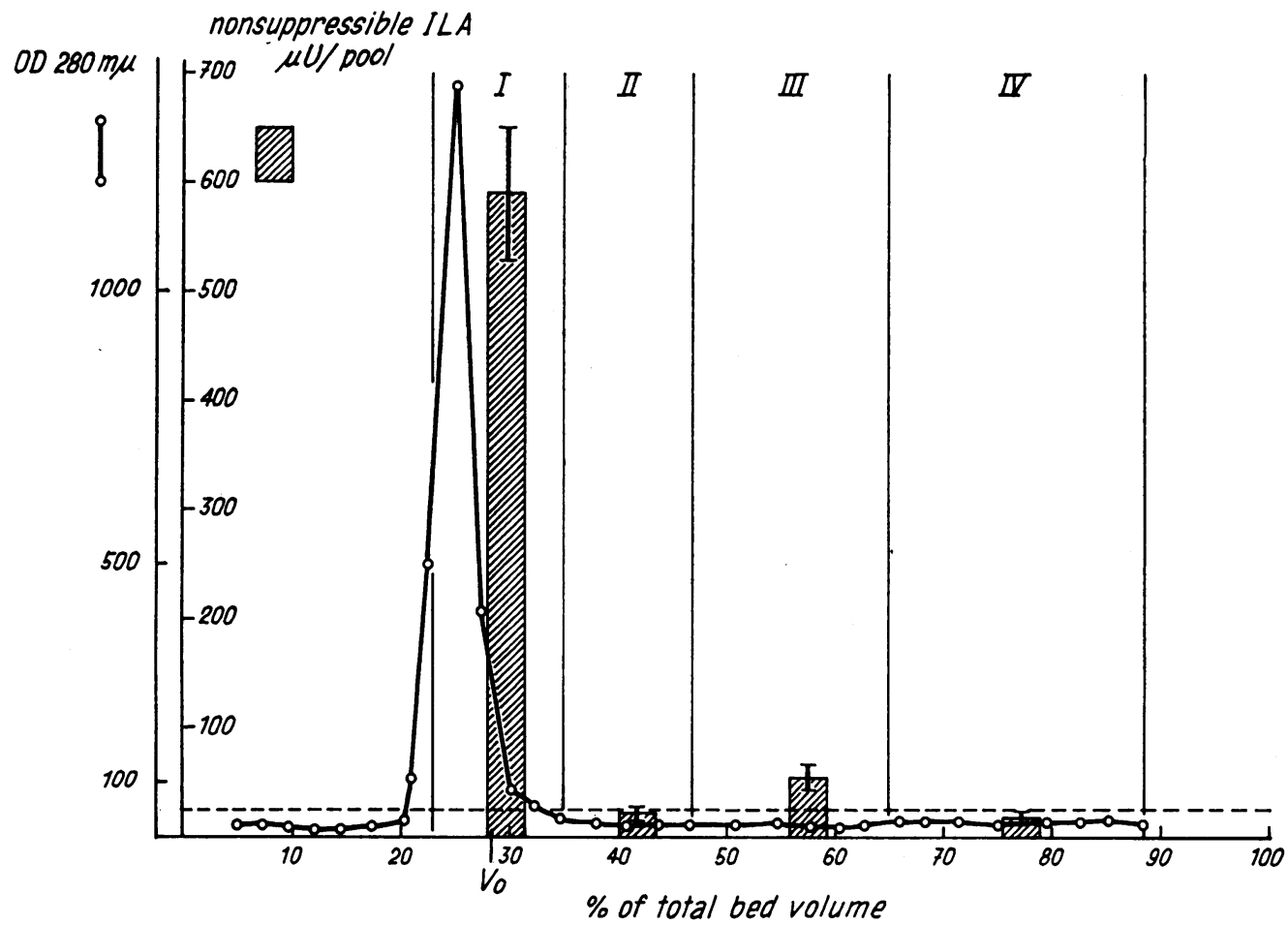

FIGURE 2 Chromatography of nonsuppressible ILA from acetone powder of human plasma on Sephadex G-75 ( $5 \mathrm{M}$ acetic acid- $0.15 \mathrm{M} \mathrm{NaCl}$ ). $400-\mathrm{mg}$ of acetone powder prepared from human plasma was homogenized in $6-\mathrm{ml}$ of $5 \mathrm{M}$ acetic acid- $-0.15 \mathrm{M} \mathrm{NaCl}$. The precipitate was centrifuged off. $2 \mathrm{ml}$ of the clear supernate were applied on a column of Sephadex G-75 ( 5 M acetic acid- $0.15 \mathrm{M} \mathrm{NaCl}$ ) of $2.2 \mathrm{~cm} \times 58.0 \mathrm{~cm}$. Pools of 5-10 consecutive fractions were dialysed against $\mathrm{H}_{2} \mathrm{O}$, evaporated to dryness, and redissolved in $2.5 \mathrm{ml}$ of Krebs-Ringer bicarbonate buffer for the assay of nonsuppressible ILA. Each bar gives the mean and range of duplicate determinations of nonsuppressible ILA. Values below the dotted line are not significantly different from those of unstimulated adipose tissue. 
tion medium contained less than $20 \mathrm{mg}$ of protein $/ \mathrm{ml}$. Care was taken that all the turbidities and precipitates were centrifuged off before the assay. The insulin standards contained 10 and $250 \mu \mathrm{U}$ of insulin/ml. Results of nonsuppressible ILA below $10 \mu \mathrm{U} / \mathrm{ml}$ were extrapolated. A horizontal dotted line in all figures indicates the 10 $\mu \mathrm{U} / \mathrm{ml}$ sensitivity limit of the bioassay.

\section{RESULTS}

Different molecular sizes of compounds with nonsuppressible ILA

(1) Acetone powder. In two consecutive experiments 72 and $64 \%$ of total nonsuppressible ILA present in lyophilized plasma were recovered in the acetone powder. Preliminary experiments showed that the biological activity of the acetone powder eluted from Sephadex-G-200 ( $\mathrm{pH}$ 7.2) with the same volume as nonsuppressible ILA of native serum (10). After chromatography of acetone powder on Sephadex G-75 at low $\mathrm{pH}$ (acetic acid- $\mathrm{NaCl}$ ), only a small portion of the activity eluted at $50-60 \%$ of total bed volume, which cor- responds to the elution volume of extracted and purified nonsuppressible ILA of Bürgi et al. (10) (Fig. 2). More than $90 \%$ of the eluted activity was of appreciably higher molecular weight, since it was eluted with the void volume of the column. This type of experiment was carried out several times with acetone powder of plasma and of Cohn fraction $\mathrm{B}$, each time with the same result.

(2) Acid-ethanol supernate (fraction S). Only 5.2 and $5.3 \%$ of total nonsuppressible ILA originally present in the acetone powder of serum were recovered in the acid-ethanol supernate (fraction $\mathrm{S})$ in two experiments.

Fig. 3 shows that the nonsuppressible ILA of fraction $S$ eluted from Sephadex G-75 (acetic acid- $\mathrm{NaCl}$ ) in one single peak at approximately $50 \%$ of the total bed volume. This elution volume indicated a mol wt of $6000-10,000$. These results were reproduced many times with both plasma and Cohn fraction $\mathrm{B}$ as starting material.

As shown in Fig. 4 nonsuppressible ILA of

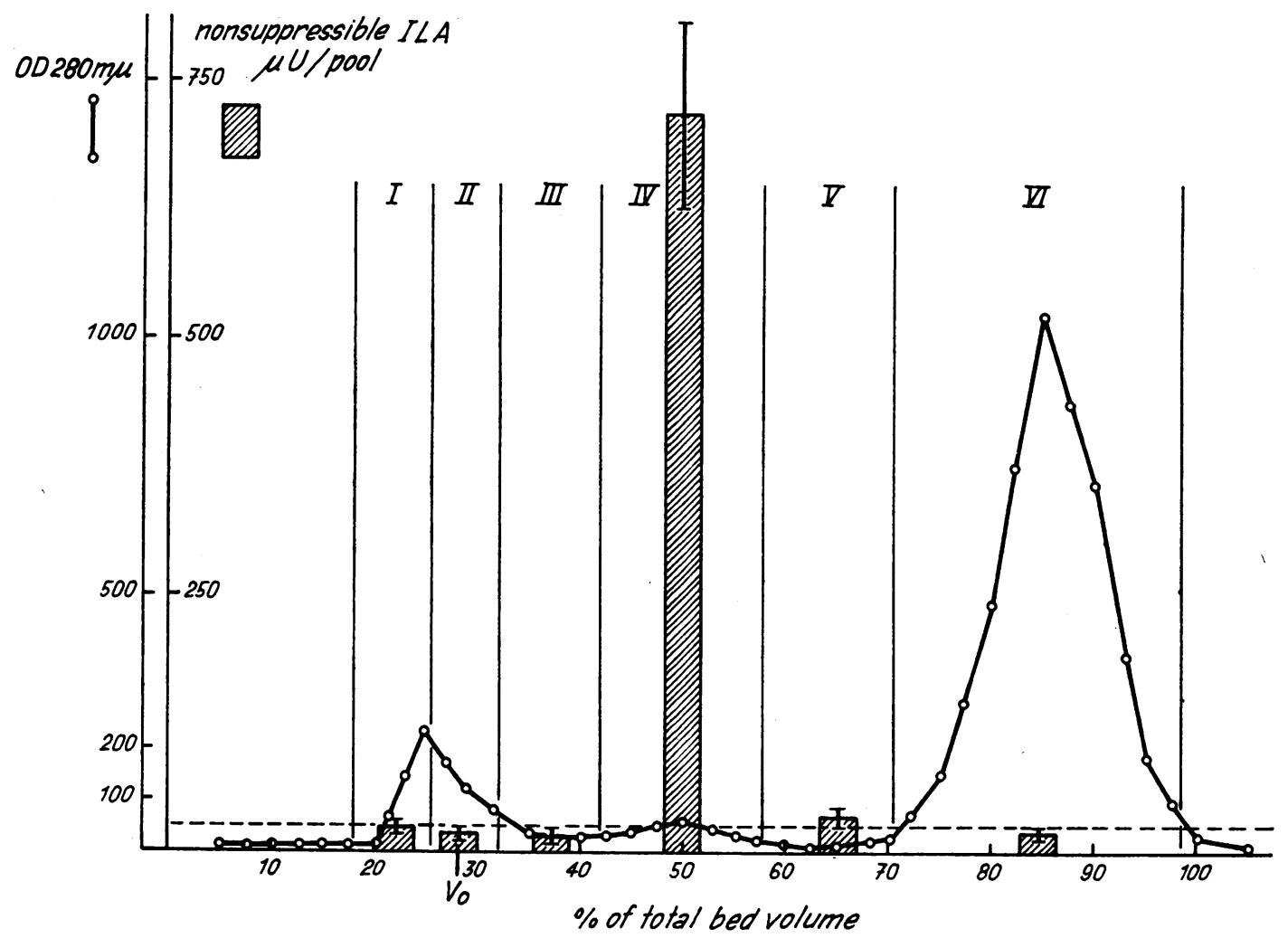

Figure 3 Gel-filtration of acid-ethanol-soluble material (fraction S) from acetone powder of human plasma on Sephadex G-75 ( $5 \mathrm{~m}$ acetic acid- $0.15 \mathrm{M} \mathrm{NaCl}$ ). For a detailed description of the technique used, see legend to Fig. 1 and Methods. 


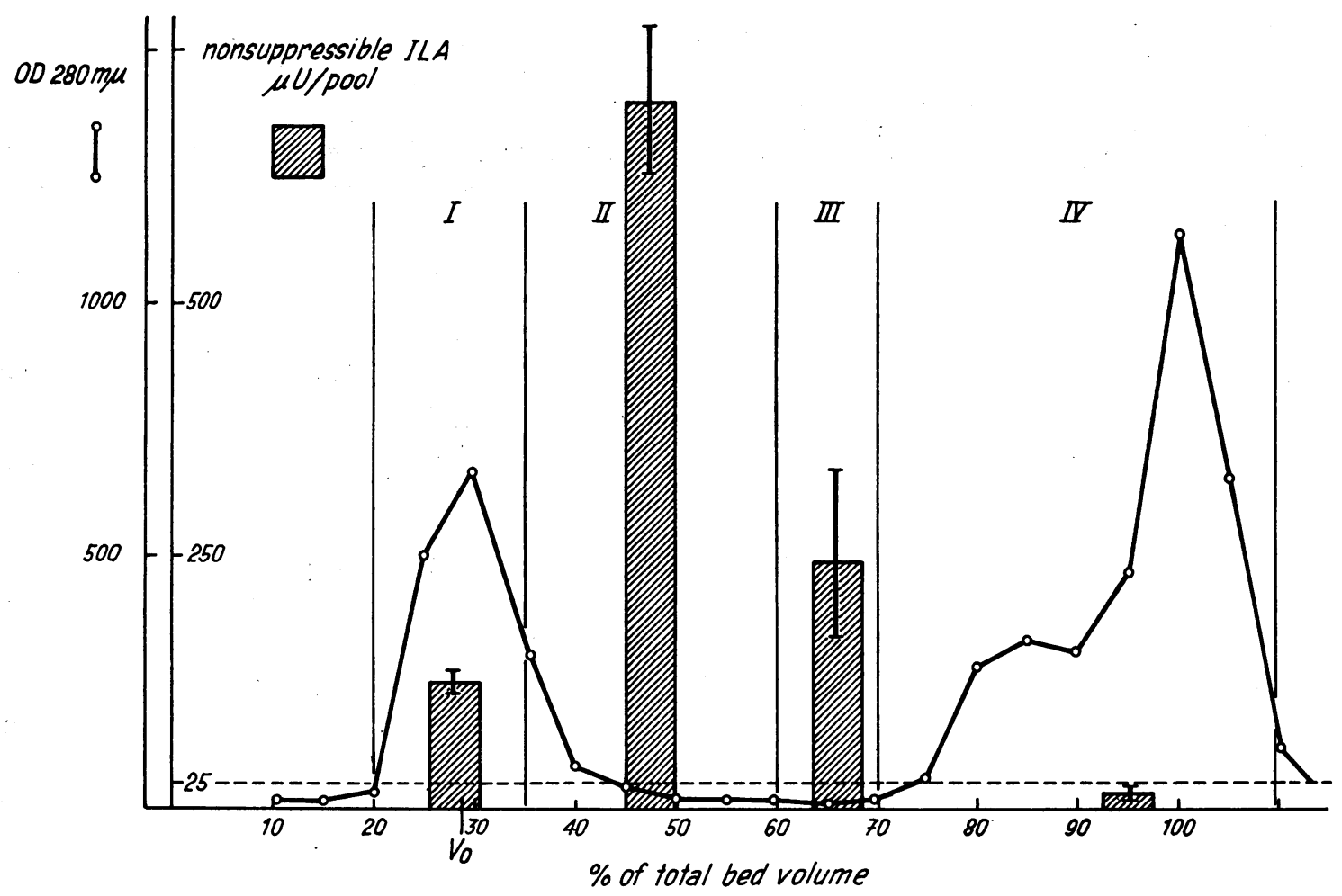

FIgURE 4 Gel-filtration of fraction S on Sephadex G-100 (0.1 м ammonium acetate, $\mathrm{pH} 7.2)$ column of $2.2 \mathrm{~cm}$ $\times 29.5 \mathrm{~cm}$. For a detailed description of the technique used, see legend to Fig. 1 and Methods.

fraction $S$ was eluted in a broad peak from a column of Sephadex G-100 at neutral pH. Although a precise estimate of the molecular weight is impossible, the major portion of the activity was eluted between 35 and $60 \%$ of the total bed volume (mol wt 20,000-80,000). In contrast to this, all of the biological activity of fraction $\mathrm{S}$ eluted in a sharp peak under conditions of low $\mathrm{pH}$ and high molarity (Fig. 3).

In the experiment shown in Fig. 5, nonsuppressible ILA of fraction $S$ was subjected to chromatography on Sephadex G-200 (pH 7.2). Compared with the experiment represented in Fig. 4, nonsuppressible ILA eluted at a higher percentage of bed volume, indicating a similar molecular size of nonsuppressible ILA on both columns.

(3) Acid-ethanol precipitate (fraction $P$ ). In two experiments 38 and $34 \%$ of the total nonsuppressible ILA present in the acetone powder were recovered after extraction and purification in fraction $P$. When applied on the column of Sephadex G-75 (acetic acid- $\mathrm{NaCl}$ ) all of this nonsuppressible ILA eluted with the void volume indicating that its mol wt was 50,000 or greater.

Since nonsuppressible ILA of fraction $\mathrm{P}$ also eluted with the void volume from Sephadex G-100, an estimate of its molecular weight was obtained by chromatography on Sephadex G-200 ( $\mathrm{pH} 7.2$ ) (Fig. 6). The biological activity was found in the same fractions as nonsuppressible ILA of native serum corresponding to a mol wt of the order of $100,000-150,000$.

\section{Relationship between different forms of ILA}

(1) No conversion of fraction $P$ to $S$. Since nonsuppressible ILA in extracts of human plasma was exerted by three compounds of different molecular weights, we became interested to find out whether or not they were chemically related.

In three experiments the same amounts of fraction $S$ were applied, both on the column equilibrated with buffer at neutral $\mathrm{pH}$ (Sephadex G-100) and on the column equilibrated with acetic acid and $\mathrm{NaCl}$ (Sephadex G-75). Setting the recovery of nonsuppressible ILA from the neutral column as $100 \%, 113 \% \pm 19 \%$ (mean \pm SEM) 
were recovered from the acid column with a molecular weight of approximately 6000 .

In two other experiments nonsuppressible ILA of fraction $\mathrm{S}$ that had been recovered from Sephadex G-100 at neutral $\mathrm{pH}$ in an elution volume corresponding to a mol wt of 20,000-80,000 (pool II, Fig. 4) was rechromatographed under acid conditions on the column of Sephadex G-75 (Fig. 7). Again, nonsuppressible ILA eluted in one single peak corresponding to a smaller mol wt in the range of about 6000 .

Since nonsuppressible ILA of fraction $\mathrm{P}$ with a mol wt of about 150,000 was not converted to a molecule of about 6000 , either by a low $\mathrm{pH}$ and high molarity or by acid-ethanol, another attempt to cleave the molecule was made with urea ( 7 м) and EDTA $(0.2 \%)$. The elution pattern from the column of Sephadex G-75 (acetic acid- $\mathrm{NaCl}$ ) did not change after this treatment and was identical with that of pool I in the experiment shown in Fig. 2.

(2) Dowex-50 chromatography of serum and of purified fractions $S$ and $P$. The biological activity of the $\mathrm{NaCl}$ wash and of the alkaline eluate together amounted to $200 \%$ of that originally measured in serum (Table I). Appreciable amounts of nonsuppressible ILA of serum were recovered in each of the two fractions. The $\mathrm{NaCl}$ wash contained most of the serum proteins and had a biological activity of only $1.5 \mu \mathrm{U} / \mathrm{mg}$. The alkaline eluate assayed about $200 \mu \mathrm{U} / \mathrm{mg}$ protein.

$27 \%$ of nonsuppressible ILA of fraction S dissolved in Krebs-Ringer bicarbonate buffer was recovered in the alkaline eluate. When dissolved in albumin or serum, increasing amounts were found in the $\mathrm{NaCl}$ wash, whereas the biological activity recovered in the alkaline eluate was constant.

Under all conditions, most of the nonsuppressible ILA of fraction $\mathrm{P}$ was present in the $\mathrm{NaCl}$ wash.

The alkaline eluate of $30-\mathrm{ml}$ of serum was chromatographed on Sephadex G-75 (acetic acid$\mathrm{NaCl}$ ). Two peaks of nonsuppressible ILA were

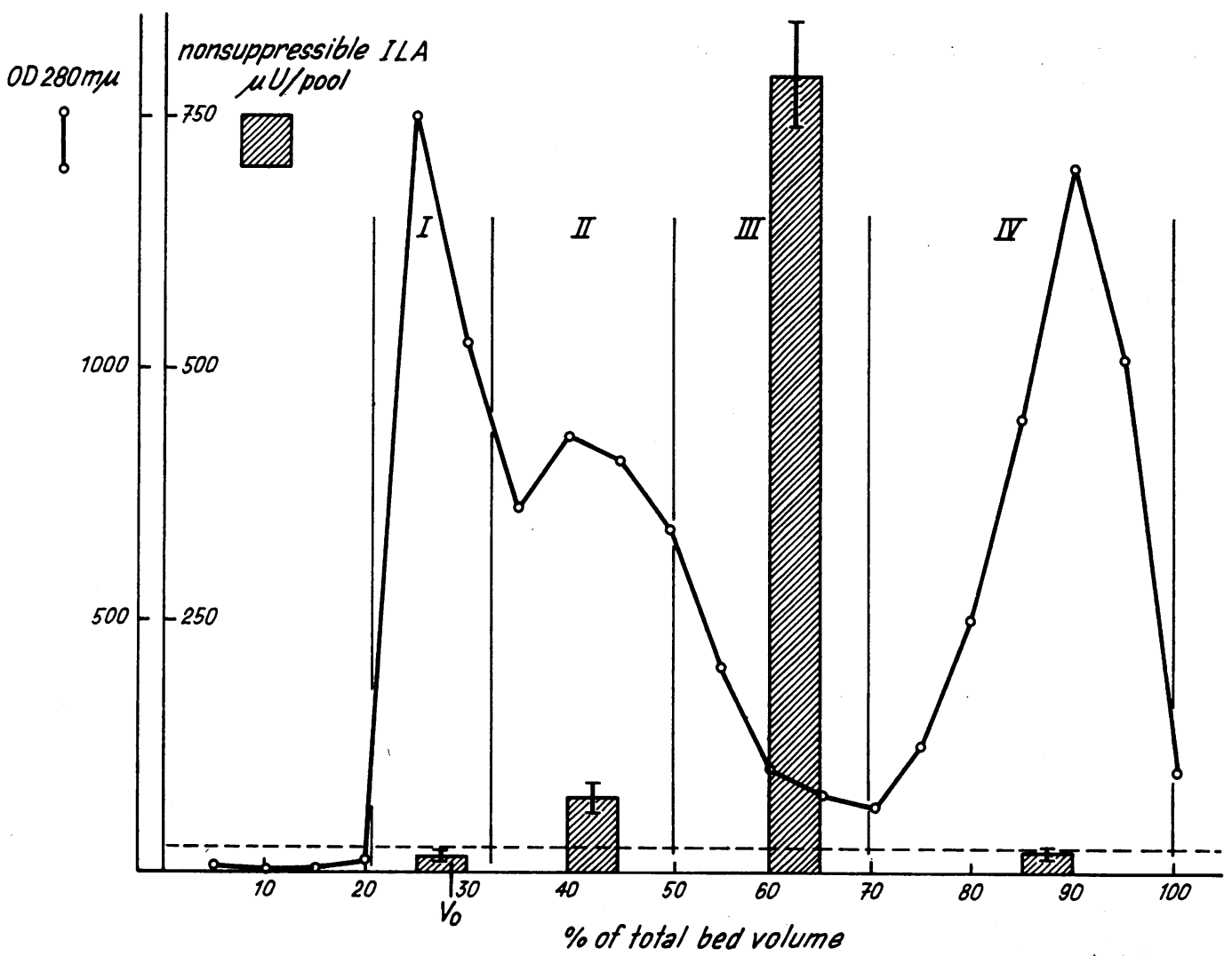

Figure 5 Gel-filtration of fraction S on Sephadex G-200 (0.1 M ammonium acetate, pH 7.2,) column of $2.2 \mathrm{~cm} \times 28.5 \mathrm{~cm}$. For a detailed description of the technique used, see legend to Fig. 1 and Methods. 


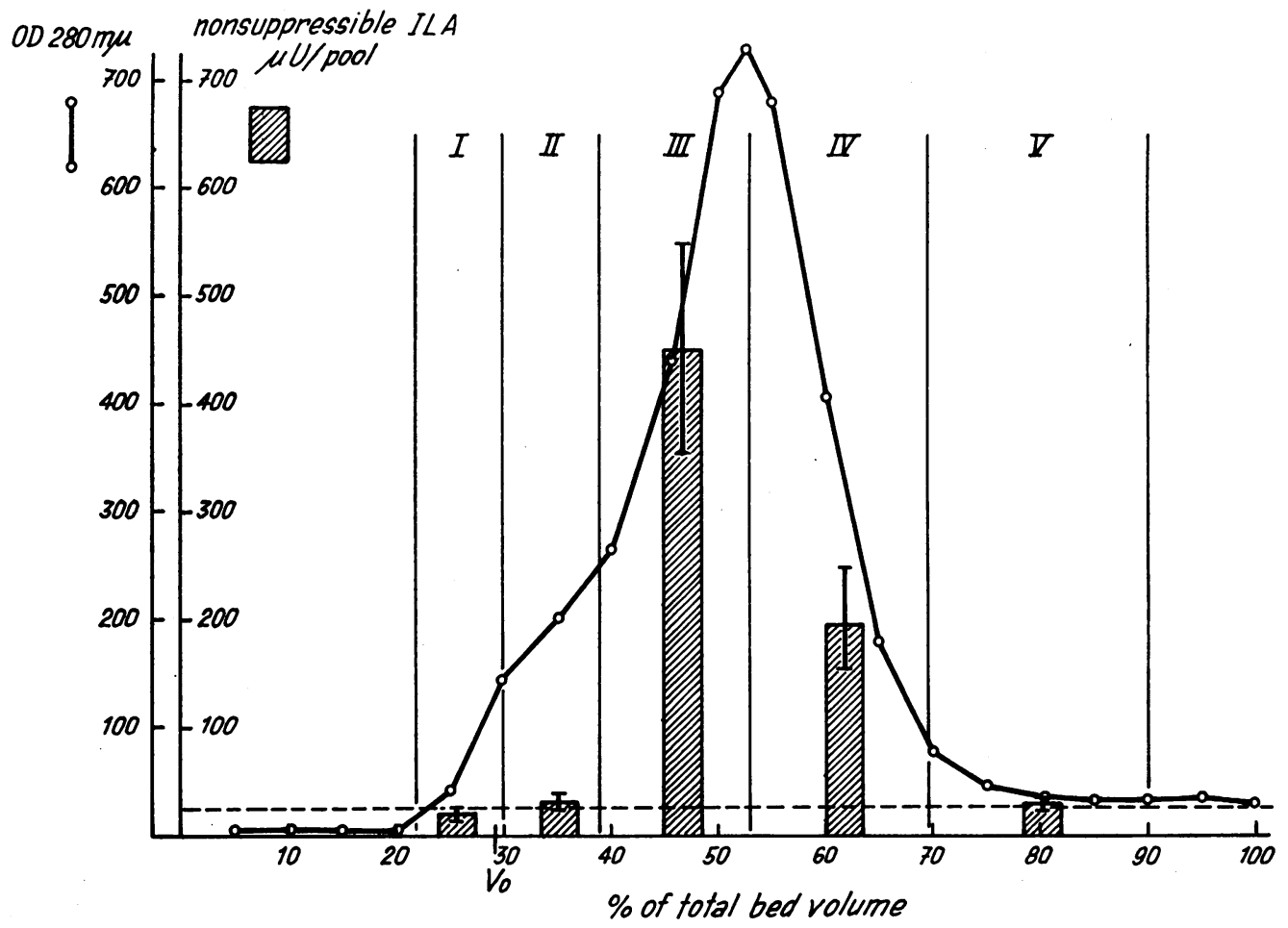

Figure 6 Gel-filtration of $50 \mathrm{mg}$ of fraction $\mathrm{P}$ on Sephadex G-200 (ammonium acetate $0.1 \mathrm{M}, \mathrm{pH}$ 7.2). For a detailed description of the technique used, see legend to Fig. 1 and Methods.

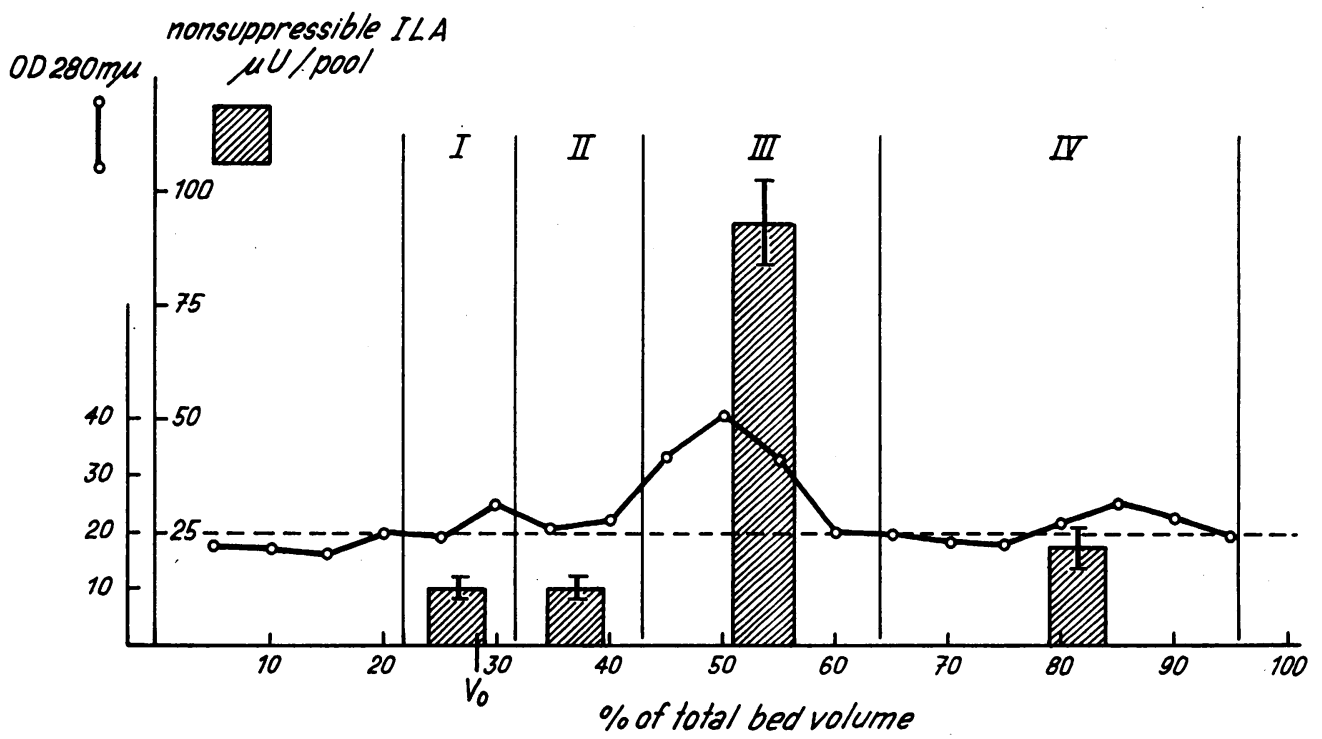

FIGURE 7 Rechromatography of fraction S, pool II (Fig. 4) on Sephadex G-75 (5 M acetic acid-0.15 $\mathrm{M} \mathrm{NaCl}$ ). Nonsuppressible ILA of pool II (Fig. 4) with an apparent mol wt of the order of 50,000 was chromatographed on a column of Sephadex G-75 (acetic acid- $\mathrm{NaCl}$ ). $60 \%$ of the biological activity was recovered in pool III, corresponding to a smaller molecular weight. 
TABLE I

Recovery of Nonsuppressible ILA from Dowex-50, with Serum, Albumin and Krebs-Ringer Bicarbonate Buffer as Solvents for Purified Fractions $S$ and $P^{*}$

\begin{tabular}{|c|c|c|c|c|c|c|c|c|c|c|c|c|}
\hline \multirow[b]{3}{*}{ Solutions applied on the column } & \multicolumn{12}{|c|}{ Additions to solutions applied on the column } \\
\hline & \multicolumn{4}{|c|}{ None } & \multicolumn{4}{|c|}{$2.5 \mathrm{mg}$ of fraction $\mathrm{S}$} & \multicolumn{4}{|c|}{$38.0 \mathrm{mg}$ of fraction $P$} \\
\hline & c $\ddagger$ & $\mathbf{w}$ & e & $\mathbf{r}$ & c & $\mathbf{w}$ & e & $\mathbf{r}$ & c & $\mathbf{w}$ & e & $\mathbf{r}$ \\
\hline & \multicolumn{12}{|c|}{$m U$ of nonsuppressible $I L A / 5 \mathrm{ml}$} \\
\hline Serum, $5 \mathrm{ml}$ & 0.9 & 0.8 & 1.0 & 200 & 5.1 & 2.6 & 0.9 & 69 & 2.6 & 4.5 & 0.0 & 173 \\
\hline $\begin{array}{l}\text { Krebs-Ringer bicarbonate buffer } \\
\text { plus albumin, } 70 \mathrm{mg} / \mathrm{ml}(5 \mathrm{ml})\end{array}$ & $<0.1$ & $<0.1$ & $<0.05$ & - & 4.5 & $<0.7$ & 0.8 & 30 & 3.7 & 3.7 & 0.3 & 108 \\
\hline $\begin{array}{l}\text { Krebs-Ringer bicarbonate buffer, } \\
\quad 5 \mathrm{ml}\end{array}$ & - & - & - & - & 4.0 & $<0.4$ & 1.1 & 37 & 4.1 & 5.4 & 0.6 & 146 \\
\hline
\end{tabular}

* For technical details, see Methods.

$\ddagger \mathrm{c}$, control value before chromatography; $w, \mathrm{NaCl}$ wash; $e$, alkaline eluate; $r$, per cent recovery of $\mathrm{c}$.

$\S$ In the sample containing fractions $\mathrm{S}, \mathrm{P}$, and serum, the serum values of nonsuppressible ILA were subtracted from the measured values.

obtained (Fig. 8). Two thirds of the biological activity recovered eluted between 50 and $70 \%$ of total bed volume. This represented $15 \%$ of the total ILA originally present in serum. A significant amount eluted in the main protein peak with the void volume of the column.

\section{Inactivation}

Nonsuppressible ILA with a mol wt of approximately 6000 was shown by Bürgi et al. (10) to lose $40-50 \%$ of its biological activity when treated with glutathione. Nonsuppressible ILA of fraction $P$ with an apparent mol wt of 150,000 was reduced

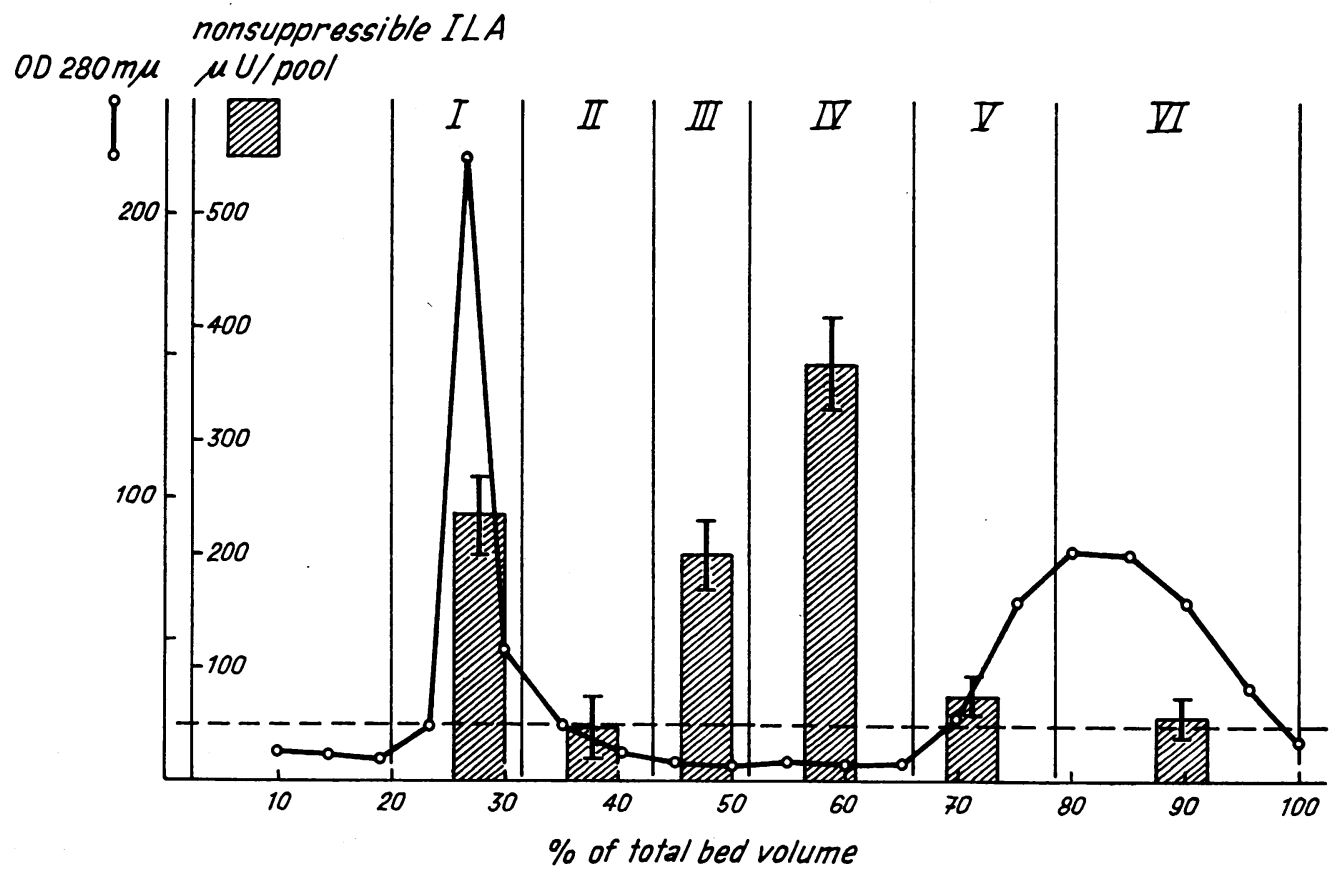

FIGURE 8 Chromatography of nonsuppressible ILA of alkaline eluate (Dowex-50) on Sephadex G-75 ( 5 M acetic acid- $0.15 \mathrm{M} \mathrm{NaCl}$ ). $30-\mathrm{ml}$ of serum was passed over Dowex-50. The alkaline eluate was lyophilized, dissolved in acetic acid- $\mathrm{NaCl}$, and chromatographed on Sephadex. Further description of technique is given in the legend to Fig. 1 and in Methods. 
to less than $10 \%$ of its initial activity by treatment with mercaptoethanol and urea. Heating to $80^{\circ} \mathrm{C}$ for $15 \mathrm{~min}$ inactivated nonsuppressible ILA of fraction $\mathrm{P}$ nearly completely, whereas the nonsuppressible ILA of smaller molecular size was shown to be heat resistant for $3 \mathrm{hr}$ under the same conditions (10).

\section{DISCUSSION}

In our present studies approximately $70 \%$ of nonsuppressible ILA present in human plasma was recovered in the acetone powder. Purification revealed that nonsuppressible ILA did not behave as a homogenous biochemical entity. Molecules of apparently three different sizes were found to be biologically active. $5-10 \%$ of total nonsuppressible ILA present in the acetone powder was soluble in acid-ethanol and appeared to be homogenous with regard to molecular size in $5 \mathrm{~m}$ acetic acid- $-0.15 \mathrm{~m}$ $\mathrm{NaCl}$. In this buffer it had a molecular weight of about $6000-10,000$, i.e., exactly the same as nonsuppressible ILA extracted by Bürgi et al. from a Cohn fraction of human plasma (10). Thus, these two extracts probably contain the same active substance.

Gel-filtration of fraction $\mathrm{S}$ (soluble in acidethanol) on Sephadex G-100 at neutral $\mathrm{pH}$ yielded an elution pattern of nonsuppressible ILA similar to that found by other authors working with Sephadex at neutral $\mathrm{pH}(18,20)$. Thus, Cameron, Boyns, Jarrett, and Keen (17) found that ILA of a trichloroacetic acid extract of human plasma eluted from Sephadex G-200 at neutral pH over a wide range. The biological activity of fraction $\mathrm{S}$ also eluted in a broad peak corresponding to a mol wt of approximately 50,000. We interpreted our findings to indicate a conversion of the compound of about $50,000 \mathrm{~mol}$ wt to one of about 6000 by treatment with acetic acid and $\mathrm{NaCl}$. This assumption was supported by the results presented in Fig. 7. These show that nonsuppressible ILA of an apparent mol wt of the order of 50,000 obtained from Sephadex G-100 ( $\mathrm{pH} \mathrm{7.2)} \mathrm{eluted} \mathrm{in} \mathrm{a} \mathrm{vol-}$ ume corresponding to a mol wt of about 6000 from Sephadex G-75 (acetic acid- $\mathrm{NaCl}$ ). Two theoretical possibilities of the generation of the small molecular species of nonsuppressible ILA must be considered. First, small molecular nonsuppressible ILA may be adsorbed to another protein with a mol wt of approximately 50,000 and may then be split off by acetic acid at high molarity. Second, molecules with nonsuppressible ILA of fraction $\mathrm{S}$ may form aggregates at neutral $\mathrm{pH}$ and may be dissociated by acetic acid. The changes induced by low $\mathrm{pH}$ and high molarity seemed to be irreversible since rechromatography of nonsuppressible ILA of small molecular weight on Sephadex at neutral $\mathrm{pH}$ yielded one single peak corresponding to a mol wt of about 6000 as previously shown by Bürgi et al. (10). The estimate of the molecular weight of nonsuppressible ILA of fraction $\mathrm{S}$ by Sephadex G-75 (acetic acid- $\mathrm{NaCl}$ ) appeared to be adequate, since it was eluted in a fairly sharp peak, whereas the peak obtained from Sephadex G-100 at neutral $\mathrm{pH}$ was broad and illdefined.

Poffenbarger et al. (18) used a column of Sephadex G-100 at neutral $\mathrm{pH}$ for the characterization of ILA extracted either by acid-ethanol or by the method reported by Antoniades et al. (20). The latter group estimated the mol wt of "bound insulin" to lie between 60,000 and 100,000 by chromatography on Sephadex G-100 at a pH of 8 (20).

Most of the nonsuppressible ILA present in the acetone powder was insoluble in acid-ethanol and had a mol wt of approximately 150,000 when estimated on a column of Sephadex G-200 ( $\mathrm{pH}$ 7.2). It was not converted to the nonsuppressible ILA of small molecular weight either by acid-ethanol or by acetic acid. It could not be dissociated into smaller fragments by urea and EDTA. In contrast to nonsuppressible ILA of fraction $\mathrm{S}$, which was thermostabile, the molecule of fraction $\mathrm{P}$ was inactivated by heat. This finding also indicated that a chemical relationship between nonsuppressible ILA soluble in acid-ethanol, and that precipitated by this reagent was very unlikely. In this respect nonsuppressible ILA of high molecular weight resembled "hepatic" ILA that was reported by Siess, Teinzer, Struck, and Wieland (21) to be inactivated by heat.

Total recovery of ILA after extraction and purification in fractions $\mathrm{P}$ and $\mathrm{S}$ together amounted to 30 to $40 \% \quad(100 \mu \mathrm{U} / \mathrm{ml}$ of serum taken as $100 \%$ ). Our finding that only $5 \%$ of total nonsuppressible ILA of native serum was soluble in acid-ethanol explained the low recovery of nonsuppressible ILA after acid-ethanol extraction of 
plasma or of a Cohn fraction of plasma $(7,10)$. Nearly $100 \%$ of the small molecular form of nonsuppressible ILA present in the acetone powder was recovered after extraction by acid-ethanol and purification on Sephadex. In contrast, only 30-40\% of nonsuppressible ILA of high molecular weight present in the acetone powder was recovered after treatment with acid-ethanol and after purification. This loss of activity may be explained by the instability of this molecule.

Recently, Poffenbarger et al. (18) suggested that "bound insulin," "atypical insulin," and nonsuppressible ILA are all one and the same substance. Two types of experiments were designed to test this hypothesis.

When fraction $\mathrm{S}$ was dissolved in buffered albumin or in Krebs-Ringer bicarbonate buffer alone, only small amounts appeared in the $\mathrm{NaCl}$ wash after Dowex chromatography. The recovery in the total eluate $(\mathrm{NaCl}$ wash + alkaline eluate) was only 30 to $40 \%$. When fraction $\mathrm{S}$ was dissolved in serum a large proportion was recovered in the $\mathrm{NaCl}$ wash. These findings suggest that nonsuppressible ILA of fraction S was retained on the resin and that it was partially inactivated during the elution with $\mathrm{NH}_{4} \mathrm{OH}$ into $\mathrm{H}_{2} \mathrm{SO}_{4}$. Since serum contains other basic proteins, these may conceivably compete for the binding sites of the resin, so that in the presence of serum nonsuppressible ILA may be eluted with the $\mathrm{NaCl}$ wash, yielding a higher total recovery. These data thus suggest that purified fraction $S$ is, indeed, retained on Dowex-50, therefore fulfilling the main criterion of "bound insulin." In contrast, most of the nonsuppressible ILA of fraction $\mathrm{P}$ was not retained on the resin. No losses of biological activity occurred during chromatography of fraction P.

In the other set of experiments "bound insulin" was prepared from serum by the method of Antoniades et al. The alkaline eluate was subjected to chromatography on Sephadex at low $\mathrm{pH}$. As clearly shown in Fig. 8, two-thirds of the biological activity recovered had an apparent mol wt of 6000 , but significant amounts also eluted in the outer volume.

Our results strongly support the hypothesis of Poffenbarger et al. (18) that "bound insulin" and nonsuppressible ILA soluble in acid-ethanol (fraction S) are the same. The controversal estimates of the molecular size clearly are due to the different conditions chosen for Sephadex chromatography. At low $\mathrm{pH}$ and high molarity most of the "bound insulin" and all of fraction S have an apparent mol wt of 6000 .

Neither "bound insulin" nor nonsuppressible ILA of fraction S account for the bulk of ILA in serum. Big molecular nonsuppressible ILA is lost in both procedures, in the $\mathrm{NaCl}$ wash and in the acid-ethanol precipitate, respectively.

The present studies demonstrate that nonsuppressible ILA of plasma results from the additive effects of at least two distinct components. Thus, any speculations about possible physiological roles $(9,12,20)$ and possible sites of formation (22) are hazardous and premature as long as total nonsuppressible ILA is measured.

\section{ACKNOWLEDGMENTS}

Valuable advice and criticism by Professor A. Labhart and Dr. R. E. Humbel is gratefully acknowledged. We are indebted to Miss S. Diem for her skilled technical assistance.

This work was supported by grant 3854 from the Schweizerische Nationalfonds and grant A 5387 from the U. S. Public Health Service.

\section{REFERENCES}

1. Renold, A. E., D. B. Martin, Y. M. Dagenais, J. Steinke, R. J. Nickerson, and M. C. Sheps. 1960. Measurement of small quantities of insulin-like activity using rat adipose tissue. I. A proposed procedure. J. Clin. Invest. 39: 1487.

2. Groen, J., C. E. Kamminga, A. F. Willebrands, and J. R. Blickman. 1952. Evidence for the presence of insulin in blood serum. A method for an approximate determination of the insulin content of blood. J. Clin. Invest. 31: 97.

3. Rasio, E. A., C. L. Hampers, J. Soeldner, and G. F. Cahill, Jr. 1967. Diffusion of glucose, insulin, inulin and Evans blue protein into thoracic duct lymph of man. J. Clin. Invest. 46: 903.

4. Quijada, C. L., and J. L. R. Candela. 1967. Insulin and insulin-like activity in the bile of rabbits. Proc. Soc. Exptl. Biol. Med. 126: 209.

5. Guevara, L. B., J. C. Meek, and R. E. Bollinger. 1967. Partial characterisation of urine protein with insulin-like activity. Proc. Soc. Exptl. Biol. Med. 125: 1049.

6. Ramseier, E. B., E. R. Froesch, P. Bally, and A. Labhart. 1962. Seruminsulinbestimmung am Fettgewebe in vitro: Beeinflussung durch andere Hormone, freie und gebundene Insulinaktivität. Abstracts from the 4th Congress of the International Diabetes Federation, Geneva. 643. 
7. Leonards, J. R., and B. R. Landau. 1962. Assay of insulin and insulin-like activity with rat epididymal fat pad. J. Lab. Clin. Med. 60: 552 .

8. Froesch, E. R., H. Bürgi, E. B. Ramseier, P. Bally, and A. Labhart. 1963. Antibody-suppressible and nonsuppressible insulin-like activities in human serum and their physiologic significance. An insulin assay with adipose tissue of increased precision and specificity. J. Clin. Invest. 42: 1816.

9. Samaan, N. A., R. Fraser, and W. J. Dempster. 1963. The "typical" and "atypical" forms of serum insulin. Diabetes. 12: 339.

10. Bürgi, H., W. A. Müller, R. E. Humbel, A. Labhart, and E. R. Froesch. 1966. Nonsuppressible insulin-like activity of human serum. I. Physicochemical properties, extraction and partial purification. Biochim. Biophys. Acta. 121: 349.

11. Froesch, E. R., W. A. Müller, H. Bürgi, M. Waldvogel, and A. Labhart. 1966. Nonsuppressible insulinlike activity of human serum. II. Biological properties of plasma extracts with nonsuppressible insulinlike activity. Biochim. Biophys. Acta. 121: 360.

12. Froesch, E. R., H. Bürgi, W. A. Müller, R. E. Humbel, A. Jakob, and A. Labhart. 1967. Nonsuppressible insulin-like activity of human serum: purification, physicochemical and biological properties and its relations to total serum ILA. Recent Progr. Hormone Res. 23: 565.

13. Williams, R. H., and J. W. Ensinck. 1966. Secretion, fates and actions of insulin and related products. Diabetes. 15: 623 .

14. Lyngsoe, J. 1965. Seruminsulin. Acta Med. Scand. Suppl. 179.
15. Batchelor, B. R. 1967. Insulin-like activity. Diabetes. $16: 418$.

16. Kuzuya, T., and E. Samols. 1964. Comparison of rat fat pad ILA and radioimmunoassay in human serum protein fractions. Abstracts from the 5th Congress of the International Diabetes Federation, series 74, Toronto.

17. Cameron, J. S., D. R. Boyns, R. J. Jarrett, and H. Keen. 1966. The properties of trichloracetic acidethanol extracts of human plasma. II. Physical, chemical and immunological properties of the extracts. Diabetologia. 2: 91.

18. Poffenbarger, P. L., J. W. Ensinck, D. K. Hepp, and R. H. Williams. 1968. The nature of human serum insulin-like activity (ILA): characterization of ILA in serum and serum fractions obtained by acid-ethanol extraction and adsorption chromatography. J. Clin. Invest. $47: 301$.

19. Solomon, S. S., P. L. Poffenbarger, D. K. Hepp, L. F. Fenster, J. W. Ensinck, and R. H. Williams. 1967. Quantitation and partial characterization of nonsuppressible insulin-like activity in serum and tissue extracts of the rat. Endocrinology. 81: 213 .

20. Antoniades, H. N., A. M. Huber, B. R. Boshell, C. A. Saravais, and S. N. Gershoff. 1965. Studies on the state of insulin in blood: properties of circulating "free" and "bound" insulin. Endocrinology. 76: 709.

21. Siess, E., A. Teinzer, E. Struck, and O. Wieland. 1965. Bildung eines insulinartigen Wirkstoffes durch die isolierte Rattenleber. Diabetologia. 1: 21.

22. Power, L., G. R. Rojas, and J. H. Londono. 1967. New evidence for islet cell origin of insulin-like activity in serum. Lancet. 1: 1123. 